\title{
Solution focused brief therapy: Concerns of school psychologists dealing with adolescents
}

\author{
Rapheal J*
}

*Corresponding author:

Dr. Jeny Rapheal, PhD, HSST Senior, Aleemul Islam Higher Secondary School, Department of Higher secondary education, Kerala, India

Email: jenyrapheal@gmail.com ORCID

Information about the article:

Received: Jan. 17, 2019

Accepted: Feb. 20, 2019

Published online: Dec. 27, 2019

Publisher

Nepal Health Research Society, Bahundhara -6, Gokarnesowor Municipality, Kathmandu, Nepal eISSN 2382-5545, ISSN 2676-1343 (Print)

(C) The Author(s). 2019

Content licensing: CC BY 4.0

\footnotetext{
ABSTRACT

Background

A shift from the psychodynamic perspectives in psychotherapy to the solution-focused "brief" techniques is a boon to the school system where constraints of time are a serious issue. SFBT is a strength-based approach. According to its assumptions, most clients want to change, they have the competence to envision the change and make it happen. At the same time, breakthrough revelations about the functioning of the adolescent brain have catapulted old beliefs in the competence of a typical adolescent to use his rational regions of the brain as situations demand. Latest neuroscientific techniques can predict not only the "kind" of changes but the pace with which changes are happening in different regions of the brain. The immature pre-frontal cortex of adolescent stand in vis-a-vis to the assumption of the SFBT that client has the competence to resolve the issue. Adding to this, a huge repository of research literature asserts that contextual factors do have an important role in the mental health of adolescents. Early shifting into solution talk during the therapeutic process may overlook contextual factors or unconscious impulses which actively collude to sustain the problem. So the purported co-construction of solution occurring between the client and therapist need not always result in intended changes and cases of relapses are common.
}

\begin{abstract}
Objectives:
The present study was an attempt to seek clarification for the doubts and misgivings usually occur in the minds of school psychologists dealing with adolescent clients. Certain questions were framed to have an orientation in the review process. How far SFBT's assumptions are compatible with the bio-psycho-social disposition of adolescence? Given the latest neuro-scientific facts about adolescent brain functioning, how congruent is SFBT's strength-based approaches with adolescents' not so competent brain dynamics? Shift to "solution talk" ---how far it is practical when the adolescent client's issues lay interwoven with many psycho-social factors? What past research has to say about the process of SFBT rather than the outcome of SFBT?
\end{abstract}

\section{Materials and methods}

Sixty-seven papers comprising empirical studies, metaanalyses, conceptual papers dealing with various aspects of SFBT were reviewed for the purpose. ERIC, Psych INFO, Google, Medline, and PUBMED were the major database depended for retrieving the literature. Aspects of SFBT such as "briefness", focus on the solution (rather than the problem), therapeutic alliance, adherence to the trust in positive-strengths of the client ---all these were explored for their compatibility with the unique developmental characteristics of adolescence.

\section{Conclusion}

Worldwide efforts are in place to elicit novel ways of understanding and working with adolescents. SFBT technique must be customized to meet and unique needs and characteristic of the adolescent group. There are a host of researchers and therapists who believe that adolescent and child treatments will be more effective if the frame and structure of the therapy are tailored to the developmental level and characteristics of the clients. The present review about SFBT reached the same conclusions and has tentatively produced suggestions (with proper rationale) for re-orientation.

\section{Keywords}

adolescents, brain science, brief therapy, school psychology, solution focused, neuroscience 